\title{
Isolation, Characterization, Determination of Probiotic Properties of Lactic Acid Bacteria from Human Milk
}

\author{
${ }^{1}$ J. R. Kavitha and ${ }^{2}$ T. Devasena \\ ${ }^{1}$ Lecturers, Department of Biotechnology, Mother Teresa Women's University, Kodaikanal, India \\ ${ }_{2}$ Assistant Professor, Anna University, Chennai, India
}

\begin{abstract}
Probiotic mean live microorganisms that have beneficial effects on their host's health. Although probiotic strains can be isolated from many sources; for human applications the main criteria is being human origin. Breast milk is an important nutrient source for neonates. Lots of studies showed that this fluid has beneficial effects on the health of neonates. One reason of being beneficial is explaining by the micro flora of human breast milk including beneficial lactic acid bacteria. In this study, isolates were identified by biochemical and molecular characterization and also probiotic properties of lactic acid bacteria, isolated from human milk were investigated. Two of the isolates were observed as potential probiotic. Two of them are bacilli. These isolates showed resistance to stomach $p H$ ( $p H$ 3.0), tolerance against 0,3\% bile concentration and antimicrobial activity against, Escherichia coli, Bacillus ceruse and Staphylococcus aureus and. After investigation the probiotic properties of these isolates, they were identified by biochemical characterization techniques and molecular identification by using Polymeric chain Reaction (PCR) of $16 \mathrm{~S}$ ribosomal RNA (rRNA) and $16 S$ sequencing. Two lactobacilli were identified as Lactobacillus rhamnosus (KF477283) and Lactobacillus casei. (KF477282) In the light of this study, it is observed that, human milk is a source of potential probiotic strains.
\end{abstract}

Keywords: PCR-Polymeric chain reaction, RNA-ribosomal RNA

\section{Introdution}

The word 'probiotic' comes from Greek language 'pro bios' which means 'for life' opposed to 'antibiotics' which means 'against life'. The history of probiotics began with the history of man by consuming fermented foods that is well known Greek and Romans consume very much (Gismondo, et al. 1999, Guarner, et al. 2005). In 1908 a Russian researcher Ellie Metchnikoff, who has a nobel prize, firstly proposed the beneficial effects of probiotic microorganisms on human health. Metchnikoff hypothesized that Bulgarians are healthy and long lived people because of the consumption of fermented milk products which consists of rod shaped bacteria (Lactobacillus spp.). Therefore, these bacteria affect the gut microflora positively and decrease the microbial toxic activity (Gismondo, et al. 1999, Çakır 2003, Chuayana, et al. 2003).

Probiotics are also challinging for the industrial applications. The probiotic concept is open to lots of different applications in a large variety of fields relevant for human and animal health. Probiotic products consist of different enzymes, vitamins, capsules or tablets and some fermented foods contain microorganisms which have beneficial effects on the health of host. They can contain one or several species of probiotic bacteria.

Most of products which destine human consumption are produced in fermented milk or given in powders or tablets. These capsules and tablets do not used for medicinal applications. They are just used as health supporting products. The oral consumption of probiotic microorganisms produces a protective effect on the gut flora.

Lots of studies suggest that probiotics have beneficial effects on microbial disorders of the gut, but it is really difficult to show the clinical effects of such products. The probiotic preperations use for traveller's diarrhoea, antibiotic associated diarrhoea and acute diarrhoea which is showned that they have positive therapeutic effect (Gismondo,et al. 1999, Çakır 2003, Quwehand 1999).

The studies on the microbiology of human milk are restricted to the identification of potential pathogenic bacteria in clinical cases of mastitis or infant infections. However, it is clear that the prevention of infant from infectious diseases owing to the natural flora of human milk (Martín, et al. 2004). Although there are limited knowledge about the commensal or probiotic bacteria that breast milk contain, bacteria commonly isolated from this biological fluid include staphylococci, streptococci, micrococci, lactobacilli and enterococci (Martín, et al. 2004, Martín, et al. 2003, Martín, et al. 2005, Heikillä and Saris 2003). Bacteria from these genera can be easily isolated from fresh milk of healthy women. So, these groups of bacteria should be considered the natural microbiota of human milk rather than mere contaminant bacteria (Martín, et al. 2004, Martín, et al. 2005).

There are surprisingly not so much studies on the isolation and analysis of commensal or potential probiotic bacteria from breast milk (Martin, et al., 2003). However, if the bacteria with the ability to provide 
health benefits such as protection the host from pathogenic bacteria were isolated from human milk, they would be considered attractive probiotic organisms (Martín, et al. 2004). These isolated bacteria would fulfill some of the main criteria like being human origin, adaptation to dairy substrates and a histoy of long duration and safeintake by infants (Martín, et al. 2004, Klaenhammer and Kullen 1999).

\section{Materials and Methods}

Isolation of Lactic Acid Bacteria from Human Breast Milk

The isolation material was human milk obtained from 40 healthy mother volunteers in $\mathrm{KMCH}$ hospital, Coimbatore and Kodaikanal government hospital and KHMS Hospital. The samples were collected in sterile carriers and stored on ice until delivery to the laboratory. Once delivered to the laboratory, they were taken to the procedure for isolation. Pour plate technique was used to isolate the organisms. Samples were used directly and also diluted to 10-1, 10-2 and 10-3 using sterile peptone water. $1 \mathrm{ml}$ aliquot of the samples and dilutions were plated into MRS(M an, Rogosa and Sharpe) agar (pH 6.2 and pH5.5), TPY (Trypticase Phytone Yeast) agar ( $\mathrm{pH}$ 6.5) and MRS-cystein agar ( $\mathrm{pH}$ 5.5). The plates were incubated at $37^{\circ} \mathrm{C}$ for 3 days under anaerobic conditions (in anaerobe jar using Oxoid anaerogen compact). The using of these mediums aimed to isolation and enumeration of lactobacilli, streptococci and enterococii. After incubation, individual colonies were selected and transferred into sterile broth mediums. The following step is purifying the selected colonies with streak plate technique. The isolates were examined according to their colony morphology, catalase reaction and gram reaction. Gram positive and catalase negative cocci and bacilli colonies were taken to the glycerol stocks as lactic acid bacteria.

\section{Gram Staining}

The gram reaction of the isolates was determined by light microscopy after gram staining. LAB are known to be gram positive. It means that they give blue-purple color by gram staining. Cultures were grown in appropriate mediums at $37^{\circ} \mathrm{C}$ for $24 \mathrm{~h}$ under anaerobic conditions. Cells from fresh cultures were used for gram staining. After incubation cultures were transferred aseptically into $1.5 \mathrm{ml}$ eppendorf tubes and centrifuged for 5 min at $6000 \mathrm{rpm}$. Then, supernatant was removed and cells were resuspended in sterile 23 water. Gram staining procedure was applied. Then, under light microscopy gram Positives and purified isolates were determined.

\section{Catalase Test}

Catalase is an enzyme produced by many microorganisms that breaks down the hydrogen peroxide into water and oxygen and causes gas bubbles. The formation of gas bubbles indicates the presence of catalase enzyme.

$$
2 \mathrm{H} 2 \mathrm{O} 2 \rightarrow 2 \mathrm{H} 2 \mathrm{O}+\mathrm{O} 2
$$

Catalase test was performed to isolates in order to see their catalase reactions. For this purpose, two methods can be applied. Overnight cultures of isolates were grown on MRS agar at suitable conditions. After 24 h $3 \%$ hydrogen peroxide solution was dropped onto randomly chosen colony. Also fresh liquid cultures were used for catalase test by dropping $3 \%$ hydrogen peroxide solution onto $1 \mathrm{ml}$ of overnight cultures. The isolates, which did not give gas bubbles, were choosed. Since, LAB is known as catalase negative.

\section{Long Term Preservation of Isolates}

Gram positive and catalase negative isolates were preserved in MRS broth Medium containing 20\% $(\mathrm{v} / \mathrm{v})$ glycerol as frozen stocks at $-80{ }^{\circ} \mathrm{C}$. The glycerol stocks of samples were prepared by mixing $0.5 \mathrm{ml}$ of active cultures and $0.5 \mathrm{ml}$ MRS medium including $40 \%$ sterile glycerol.

\section{Probiotic Properties of Isolates}

For the determination of probiotic properties of isolates these major selection criteria were choused: resistance to low $\mathrm{pH}$, tolerance against bile salt and the Antimicrobial activity.

\section{Resistance to Low pH}

Resistance to $\mathrm{pH} 3$ is often used in vitro assays to determine the resistance to stomach $\mathrm{pH}$. Because the foods are staying during $3 \mathrm{hrs}$, this time limit was taken into account (Prasad, et al. 1998). For this purpose, active cultures (incubated for 16-18 h) were used. Cells were harvested by centrifugation for $10 \mathrm{~min}$ at $5000 \mathrm{rpm}$ and $4{ }^{\circ} \mathrm{C}$. Pellets were washed once in phosphate-saline buffer (PBS at $\mathrm{pH}$ 7.2). Then cell pellets were resuspended in PBS (pH 3) and incubated at $37^{\circ} \mathrm{C}$. Viable microorganisms were enumerated at the 0., 1., 2. and 3. Hours with pour plate techniques. Appropriate dilutions were done and plates were incubated at $37{ }^{\circ} \mathrm{C}$ under anaerobic conditions for $48 \mathrm{~h}$. Also growth was monitored at OD620 (Thermo Multiskan EX). 


\section{Tolerance against Bile}

Because the mean intestinal bile concentration is believed to be $0.3 \%(\mathrm{w} / \mathrm{v})$ and the staying time of food in small intestine is suggested to be $4 \mathrm{~h}$ (Prasad, et al. 1998). The experiment was applied at this concentration of bile for $4 \mathrm{~h}$. MRS medium containing $0.3 \%$ bile (Oxoid) was inoculated with active cultures (incubated for 16-18 h). During the incubation for $4 \mathrm{~h}$, viable colonies were enumerated for every hour with pour plate technique and also growth was monitored at OD620 (Thermo Multiskan EX).

\section{Antimicrobial Activity}

For the antimicrobial activity test, spot on lawn method was used. After $18 \mathrm{~h}$ incubation active cultures were spotted on the surface of MRS agar plates ( 2 strains for each plate). Then MRS plates were incubated to grow cultures for $24 \mathrm{~h}$ at $37{ }^{\circ} \mathrm{C}$ under anaerobic conditions. The next step is preparing the indicator microorganisms (Table 2.1). Overnight indicator pathogens inoculated (1\%) to soft agar containing $0.7 \%$ agar and this inoculated agar were overlaid on MRS plates. These plates were incubated according to the appropriate conditions for indicator microorganisms. At the end of the incubation, inhibition zone diameters (surrounding the spotted isolates) were measured. Lots of researches were observed to give the results. Accordingly; isolates, which gave an inhibition zone bigger than $1 \mathrm{~mm}$, were determined to have antimicrobial activity.

\section{Indicator microorganism Incubation conditions}

Bacillus cerus $37^{\circ} \mathrm{C}$ in TSB medium

Escherichia coli $37^{\circ} \mathrm{C}$ in TSB medium

Staphylococcus aures $37^{\circ} \mathrm{C}$ in Nutrient broth medium

\section{Physiological and Biochemical Characterization}

Biochemical tests were run according to methods offered by Bulut, 2003.

\section{Gas Production from Glucose}

In order to determine the homonfermentative and heterofermentative characterization of isolates, $\mathrm{CO} 2$ production from glucose test was applied. Citrate lacking MRS broths and inverted Durham tubes were prepared and inoculated with $1 \%$ overnight fresh cultures. Then the test tubes were incubated at $37{ }^{\circ} \mathrm{C}$ for 5 days. Gas occurrence in Durham tubes was observed during 5 days which is the evidence for $\mathrm{CO} 2$ production from glucose.

\section{Growth at Different Temperatures}

Temperature test media, MRS containing bromecresol purple indicator, was prepared and transferred into tubes as $5 \mathrm{ml}$. Then fifty $\mu \mathrm{l}$ of overnight cultures inoculated to tubes and incubated for 7 days at $10{ }^{\circ} \mathrm{C}, 15$ ${ }^{\circ} \mathrm{C}, 45{ }^{\circ} \mathrm{C}$. During these incubation time cells growth at any temperatures was observed by the change of the cultures, from purple to yellow.

\section{Growth at Different $\mathrm{NaCl}$ Concentrations}

Isolates were tested for their tolerance against different $\mathrm{NaCl}$ concentrations. For this purpose $4 \%$ and $6.5 \% \mathrm{NaCl}$ concentrations were selected. Test mediums containing bromecresol purple indicator were prepared according to the appropriate concentrations and transferred into tubes in $5 \mathrm{ml}$. these tubes were inoculated with $1 \%$ overnight cultures and then incubated at $37^{\circ} \mathrm{C}$ for 7 days. The change of the color from purple to yellow was proofed the cell growth.

\section{Arginine Hydrolysis Test}

Arginine MRS medium and Nessler's reagent were used in order to see ammonia production from arginine. MRS containing $0.3 \% \mathrm{~L}$-arginine hydrocloride was transferred into tubes as $5 \mathrm{ml}$ and inoculated with $1 \%$ overnight cultures. Tubes were incubated at $37^{\circ} \mathrm{C}$ for $24 \mathrm{~h}$. After incubation, $100 \mu \mathrm{l}$ of cultures transferred onto a white background. The same amount of Nessler's reagent was pipetted on the cultures. The change in the color was observed. Bright orange color indicated a positive reaction while yellow indicated the negative reaction. A negative control, which did not contain arginine, was also used as negative control.

\subsubsection{Carbohydrate Fermentations}

Isolates were characterized according to their fermentation profiles of ability to ferment 17 different carbohydrates. All reactions were performed by using 96-well microtitre plates. Active cells and sugar solutions were prepared separately. For preparation of active cells; isolates were activated in $10 \mathrm{ml} \mathrm{MRS}$ medium and incubated at $37^{\circ} \mathrm{C}$ for $24 \mathrm{~h}$. Then, they were centrifuged $10 \mathrm{~min}$ at $10000 \mathrm{rpm}$. Pellets were washed twice and resuspended in MRS without glucose and containing $\mathrm{pH}$ indicator bromecresol purple. Each sugar solutions 
were prepared at a final concentration of $10 \%(\mathrm{w} / \mathrm{v})$, only salicin was prepared at concentration of $5 \%$. Then the solutions were filter sterilized with filters $(0.22 \mu \mathrm{m}$ pore diameter). After preparation steps the procedure was applied. Forty $\mu \mathrm{l}$ of sugar solutions were pipetted into each well and $160 \mu \mathrm{l}$ of suspended cells were added onto the sugar solutions. Thus, $2 \%$ final sugar concentration was obtained. All the reactions were performed twice.

Also positive and negative controls were used to indicate any contamination. $160 \mu \mathrm{l}$ of suspended cells $+40 \mu \mathrm{l}$ of glucose solution were used as positive control while $200 \mu \mathrm{l}$ of suspended cells was used as negative one. After overnight incubation at $37^{\circ} \mathrm{C}$, the turbidity and the color change from purple to yellow was recorded as positive fermentation results compared with the positive and negative controls. Also results were compared with the absorbance of samples read at $620 \mathrm{~nm}$ in an automated microplate reader (Thermo Multiskan EX).

\section{The Protocol Of Sequencing Service}

1. Sequencing Kit: ABI PRISM ${ }^{\circledR}$ BigDyeTM Terminator Cycle Sequencing Kits

2. Sequencer: ABI PRISM ${ }^{\circledR}$ 3730XL Analyzer (96 capillary type) (Over 20)

3. PCR machine: MJ Research PTC-225 Peltier Thermal Cycler

4. Sequencing protocol

Sequencing reactions were performed in a MJ Research PTC-225 Peltier Thermal Cycler using a ABI PRISM ${ }^{\circledR}$ BigDyeTM Terminator Cycle Sequencing Kits with AmpliTaq ${ }^{\circledR}$ DNA polymerase (FS enzyme) (Applied Biosystems), following the protocols supplied by the manufacturer. Single-pass sequencing was performed on each template using [Universial or what you selected] primer. The fluorescent-labeled fragments were purified from the unincorporated terminators with an ethanol precipitation protocol. The samples were resuspended in distilled water and subjected to electrophoresis in an ABI 3730xl sequencer (Applied Biosystems).

\section{Primer information:}

\begin{tabular}{|c|c|c|c|c|}
\hline Primer Name & Type & Type2 & Sequence (5 to 3) \\
\hline $1518 \mathrm{~F}$ & Universal & Forward & CCAgCAgCCgCggTAATACg \\
\hline $2800 \mathrm{R}$ & Universal & Reverse & TACCAgggTATCTAATCC \\
\hline $327 \mathrm{~F}$ & Universal & Forward & AgAgTTTgATCMTGGCTCAg \\
\hline $41492 \mathrm{R}$ & Universal & Reverse & TACggYTACCTTgTTACgACTT \\
\hline
\end{tabular}

Note:

Primer $1 \& 2$ for Sequencing Reference.

Primer $3 \& 4$ for PCR Amplification

\section{Preparation of Template Dna}

\section{Analysis Procedure}

It is important to use a pure cultivated bacterium for identification. Colonies are picked up with a sterilized toothpick, and suspended in $0.5 \mathrm{~m} \ell$ of sterilizes saline in a $1.5 \mathrm{~m} \ell$ centrifuge tube. Centrifuged at $10,000 \mathrm{rpm}$ for $10 \mathrm{~min}$. After removal of supernatant, the pellet is suspended in $0.5 \mathrm{~m} \ell$ of Insta Gene Matrix (Bio-Rad, USA). Incubated $56^{\circ} \mathrm{C}$ for $30 \mathrm{~min}$ and then heated $100^{\circ} \mathrm{C}$ for $10 \mathrm{~min}$. After heating, supernatant can be use for PCR.

\section{PCR}

Add $1 \mu \ell$ of template DNA in $20 \mu l$ of PCR reaction solution. Use 27F/1492R primers for bacteria, and then perform 35 amplification cycles at $94^{\circ} \mathrm{C}$ for $45 \mathrm{sec}, 55^{\circ} \mathrm{C}$ for $60 \mathrm{sec}$, and $72^{\circ} \mathrm{C}$

for $60 \mathrm{sec}$. DNA fragments are amplified about $1,400 \mathrm{bp}$ in the case of bacteria. Include a positive control (E.coli genomic DNA) and a negative control in the PCR.

\section{Purification of PCR Products}

Remove unincorporated PCR primers and dNTPs from PCR products by using Montage PCR Clean up kit (Millipore). 


\section{SEQUENCING.}

The purified PCR products of approximately 1,400 bp were sequenced by using 2 primers as described (Primer Name File). Sequencing was performed by using Big Dye terminator cycle sequencing kit (Applied BioSystems, USA). Sequencing products were resolved on an Applied Biosystems model 3730XL automated DNA sequencing system (Applied BioSystems, USA).

\section{Resistance to Low pH}

\section{Result and Discussion}

Being resistant to low $\mathrm{pH}$ is one of the major selection criteria for probiotic strains (Quwehand, et al. 1999, Çakır 2003). Since, to reach the small intestine they have to pass through from the stressful conditions of stomach (Chou and Weimer 1999, Çakır 2003). Although in the stomach, $\mathrm{pH}$ can be as low as 1.0, in most in vitro assays $\mathrm{pH} 3.0$ has been preferred. Due to the fact that a significant decrease in the viability of strains is often observed at pH 2.0 and below (Prasad, et al. 1998).For selection the strains resistant to low pH, PBS pHadjusted to 3.0 was used. The time that takes during the digestion in the stomach is 3 hours. So all the isolates were detected whether they were resistant to $\mathrm{pH} 3.0$ during 3 hours. After the examination of all the isolates, the isolates that survive in $\mathrm{pH} 3.0$ were taken to the next step. According to this experiment only three isolates were resistant to low $\mathrm{pH}$. Two of them are bacilli. Experiments were run twice. Results, both cfu (colony forming units) values and OD620,

\section{Tolerance against Bile}

The strains, resistant to low $\mathrm{pH}$, were screened for their ability to tolerate the bile salt. Although the bile concentration of the human gastro intestinal tract varies, the mean intestinal bile concentration is believed to be $0.3 \% \mathrm{w} / \mathrm{v}$ and the staying time is suggested to be $4 \mathrm{~h}$ (Prasad, et al. 1998). Strains were detected in $0.3 \%$ during 4 hours. The cfu values and OD620 were observed. According to the results all of the isolates are resistant to $0.3 \%$ bile salt. All of the isolates are also able to grow in $0.3 \%$ bile salt as they survive.

\section{Antimicrobial Activity}

The selected strains were examined according to their antimicrobial activity. For this purpose, strains were detected against the indicator microorganisms, Staphylococcus aureus Bacillus cerus, Escherichia coli. The diameter of inhibition zones showed that all of the isolates have antibacterial effect on the indicator microorganisms.

According to the biochemical test results Lacto bacillus casei produced gas from glucose whiledid not produces ammonia from arginine. It tolerated only $\% 2 \mathrm{NaCl}$ concentrations and only grew at $45^{\circ} \mathrm{C}$. This isolate gave positive results with the carbohydrates, glucose, xylose, ribose, arabinose, melibiose, raffinose, galactose, maltose, sucrose, fructose and lactose. Lacto bacillus returi produced both gas from glucose and ammonia from arginine. It was resistant to $\% 2$ salt concentrations and grew at $45{ }^{\circ} \mathrm{C}$. This isolate gave positive test results with sugars, glucose, ribose, arabinose, trehalose, melibiose, raffinose, galactose, maltose, sucrose, fructose and lactose. When these biochemical test results are compared with the literature information, it seems that Lactobacillus rhamnosus (KF477283) and Lactobacillus casei. (KF477282).

TABLE - 1 BIO - CHEMICAL TEST

\begin{tabular}{|c|c|c|c|c|c|}
\hline Isolates & $\begin{array}{l}\text { Eijkman's } \\
\text { Test }\end{array}$ & Indole & Methyl Red & $\begin{array}{l}\text { Voges } \\
\text { Proskauer }\end{array}$ & $\begin{array}{l}\text { Citrate } \\
\text { Utilisation }\end{array}$ \\
\hline 1 & + & + & + & - & - \\
\hline 2 & + & + & + & - & - \\
\hline 3 & + & + & + & - & - \\
\hline 4 & + & + & + & - & - \\
\hline 5 & + & + & + & - & - \\
\hline 6 & + & + & + & - & - \\
\hline 7 & + & + & + & - & - \\
\hline 8 & + & + & + & - & - \\
\hline 9 & + & + & + & - & - \\
\hline 10 & + & + & + & - & - \\
\hline
\end{tabular}

+ Positive - Negative 
TABLE - 1 SUGAR FERMENTATION TEST

\begin{tabular}{|l|l|l|l|l|l|}
\hline Samples & Arabinose & Sucrose & Lactose & Xylose & Cellobiose \\
\hline 1 & + & + & + & + & - \\
\hline 2 & + & + & + & + & - \\
\hline 3 & + & + & + & + & - \\
\hline 4 & + & + & + & + & - \\
\hline 5 & + & + & + & + & - \\
\hline 6 & + & + & + & + & - \\
\hline 7 & + & + & + & + & - \\
\hline 8 & + & + & + & + & - \\
\hline 9 & + & + & + & + & - \\
\hline 10 & + & + & + & + & - \\
\hline
\end{tabular}
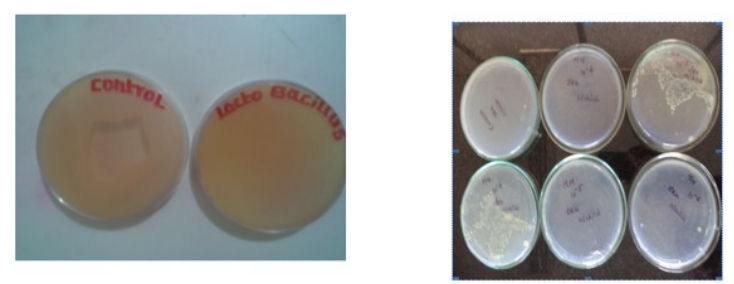

Mothers milk samples in different serial dilution of $10^{-} 3$ and $10^{-} 4$

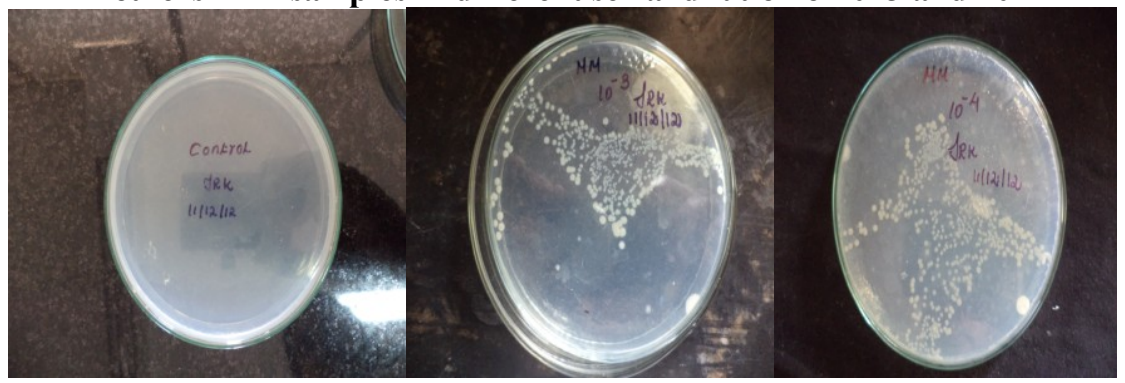

Table-2 Genera of bacteria identified of the isolate from the breast milk sample of lactating women in 16srna sequencing

\begin{tabular}{|l|l|l|l|}
\hline S.NO & IDENTIFIED ISOLATES & MAX IDENT & GEN BANK ACCESSION NO \\
\hline 1. & Lactobacillus casei & $99 \%$ & KF477282 \\
\hline 2. & Lactobacillus rhamnosus & $99 \%$ & KF477283 \\
\hline
\end{tabular}

\section{Conclusion}

After DNA isolation 16srna region was amplified by PCR protocol. Universal primers were used to amplify the 16srna gene providing the molecular identification the isolates were identified as Lactobacillus rhamnosus (KF477283) and Lactobacillus casei. (KF477282) by performing sequencing of the 16srna amplified products. The isolates were identified with NCBI and submitted to the gene bank. Characterization and determination of probiotic properties of Lactic Acid Bacteria isolated from human milk was the aim of this study. To determine the probiotic properties different tests were applied such as resistance to low $\mathrm{pH}$ and bile salt and antimicrobial activity tests.

After the determination of potential probiotic isolates, these isolates were characterized by phenotypic and genotypic methods. For the phenotypic characterization, morphologic examination, resistance to different temperatures and salt concentrations, gas production from glucose, ammonia production from arginine, and determination of sugar fermentation profiles were applied. For molecular identification, based on 16S rRNA gene was performed and 16S DNA sequencing was applied to identify the isolates. Finally the following results were obtained;

1. Lactic Acid Bacteria were isolated from human milk.

2. Probiotic properties of isolated bacteria were determined. Only 3 of them showed resistance to low $\mathrm{pH}$, tolerance to bile salt, antimicrobial activity against some indicator microorganisms.

3. Phenotypic and genotypic identifications were effectively differentiate the isolates especially sugar fermentation patterns support the genotypic characterization results. Two of them was determined that they could be Potential probiotic strains even if some forward tests were applied. In this study the first step was taken 
to use the isolates as cultures for probiotic products. The main criteria of being probiotic strains were determined and the selected isolates were identified.

\section{References}

[1]. Angelis, M., Siragusa, S., Berloco, M., Caputo, L., Settanni, L., Alfonsi, G., Amerio,M., Grandi, A., Ragni, A., and Gobbetti, M. 2006. Selection of potential probiotic actobacilli from pig feces to be used as additives in pelleted feding. Research in Microbiology. 157:792-801.

[2]. Brady, L.J., Gallaher, D.D., Busta, F.F. 2000. The role of probiotic cultures in the prevention of colon cancer. The Journal of Nutrition. 130:410S-414S.

[3]. Bulut, C. 2003. Isolation and molecular characterization of lactic acid bacteria from cheese. IYTE Thesis of Ms.

[4]. Çakır, İ. 2003. Determination of some probiotic properties on Lactobacilli and Bifidobacteria. Ankara University Thesis of Ph.D.

[5]. Cardinal, M.J., Meghrous, J., Lacroix, C., Simard, R.E., 1997. Isolation of Lactococcus lactis strain producing inhibitory activity against Listeria. Food Biotechnology11:129.

[6]. Castagliuoluolo, I., Riegler, M.F., Valenick, L., Lamont, J.T., and Pothoulakis, C. 1999.Saccharomyces boulardii protease inhibits the effects of Clostridium difficile toxins a and $b$ in human colonic mucosa. American Society for Microbiology 67(1):302-307.

[7]. Charteris, W. P., Kelly, P. M., Morelli, L., and Collins, J.K. 1997. Selective detection, enumeration and identification of potentially probiotic Lactobacillus and Bifidobacterium species in mixed bacterial populations. International Journal of Food Microbiology 35:1-27.

[8]. Chou, L.S and Weimer, B. 1999. Isolation and characterization of acid and bile tolerant isolates from strains of Lactobacillus acidophilus. Journal of Dairy Science 82:23-31.

[9]. Chuayana, Jr. E.L., V. Ponce, C., Rivera, M.R.B., Cabrera, E.C. 2003. Antimicrobial activity of probiotics from milk products. Phil J. Microbiol. Infect. Dis. 32(2):71- 74.

[10]. Chung, H.S., Kim, Y.B., Chun, S.L., and Ji, G.E. 1999. Screening and selection of acid and bile resistant Bifidobacteria. International Journal of Food Microbiology 47:25-32.

[11]. Coeuret, V., Dubernet, S., Bernardeau, M., Gueguen, M., Vernoux, J.P., 2003. Isolation, characterization and identification of lactobacilli focusing mainly on cheeses and other dairy products. Lait 83:269.50

[12]. Collins, J.K., Thornton, G., Sullivan, G.O. 1998. Selection of probiotic strains for human applications. International Dairy Journal $8: 487-490$

[13]. Dugas, B., Mercenier, A., Lenoir-Wijnkoop, I., Arnaud, C., Dugas, N., and Postaire, E.1999. Immunity and probiotics. Trends Immunology Today 20(9):387-390.

[14]. Dunne, C., Murphy, L., Flynn, S., O’Mahony, L., O’Halloran, S., Feeney, M., Morrissey, D., Thornton, G., Fitzgerald, G., Daly, C., Kiely, B., Quigley, E.M.M., O’Sullivan, G.C., Shanahan, F., and Collins, J.K. 1999. Probiotics: from myth to reality. Demonstration of functionality in animal models of disease and in human clinical trials. Antonie van Leeuwenhoek 76:279-292.

[15]. Dunne, C., O’Mahony, L., Murphy, L., Thornton, G., Morrissey, D., O’Halloran, S., Feeney, M., Flynn, S., Fitzgerald, G., Daly, C., Kiely, B., C O'Sullivan, G., Shanahan, F., and Collins J.K., 2001. In vitro selection criteria for probiotic bacteria of human origin: Correlation with in vivo findings. Am. J. Clin. Nutr. 73:386S-392S.

[16]. Favier, C.F., Vaughan, E.E., De Vos, W.M., Akkermans, A.D.L. 2002. Molecular Monitoring of succession of bacterial communities in human neonates. Appl. Environ Microbiology 68:219-226.

[17]. Fooks, L.J., Fuller, R., Gibson, G.R. 1999. Prebiotics, probiotics and human gut microbiology. International Dairy Journal 9:53-61.

[18]. Hammes, W.P., Vogel, R.F., 1995. The genus Lactobacillus. The Genera of Lactic AcidBacteria. United Kingdom: B.J.B. Wood Blackie Academic and Professional.

[19]. Heikkila, M.P. and Saris, P.E.J. 2003. Inhibition of Staphylococcus aureus by the

[20]. commensal bacteria of human milk. Journal of Applied Microbiology 95:471-478

[21]. Hirayama, K., and Rafter, J. 2000. The role of probiotic bacteria in cancer prevention. Microbes and Infection 2:681-686. 